\title{
Hepatic Arterial Infusion Chemotherapy for Metastatic Breast Cancer Patients With Resistance to Standard Systemic Chemotherapies
}

\author{
MITSUHIRO FURUTA ${ }^{1,2}$, JUNICHIRO WATANABE $^{1}$, TAKESHI ARAMAKI $^{3}$, \\ AKIFUMI NOTSU ${ }^{4}$ and HIROFUMI YASUI ${ }^{2}$ \\ ${ }^{1}$ Division of Breast Oncology, Shizuoka Cancer Center, Shizuoka, Japan; \\ ${ }^{2}$ Division of Gastrointestinal Oncology, Shizuoka Cancer Center, Shizuoka, Japan; \\ ${ }^{3}$ Division of Interventional Radiology, Shizuoka Cancer Center, Shizuoka, Japan; \\ ${ }^{4}$ Clinical Research Center, Shizuoka Cancer Center, Shizuoka, Japan
}

\begin{abstract}
Background/Aim: Hepatic arterial infusion chemotherapy (HAIC) is a treatment option for metastatic breast cancer $(M B C)$ patients with extensive liver metastasis $(L M)$; however, the appropriate regimen and the treatment effects have not been discussed. The aim of this study is to evaluate the efficacy and safety of HAIC with the 5-FU, epirubicin, and mitomycin-C (FEM) regimen. Patients and Methods: We reviewed $M B C$ patients with critical $L M$ who were resistant to standard systemic chemotherapies and had received HAIC with an FEM regimen. Results: We identified 57 patients who received HAIC between 2003 and 2017. The patient characteristics were as follows: $i)$ median age $=56(30$ 80), and ii) Eastern Cooperative Oncology Group Performance Status, $0 / 1 / 2=43 / 11 / 3$. The median number of LMs was 8 (range 1 to $\geq 20$ ), the median diameter of $L M$ was $5.2 \mathrm{~cm}$ (range $=1.6$ to 20.1). The median overall survival from the initiation of HAIC was 11.3 months $195 \%$ confidence interval=8.5-15.6). The objective response rate of $L M$ was 63\%. Conclusion: HAIC with an FEM regimen is an effective salvage treatment for MBC patients with advanced $L M$.
\end{abstract}

Breast cancer is the most common cause of cancer-related deaths in women worldwide (1). Distant metastasis is found in approximately $20 \%-30 \%$ of breast cancer patients (2), and

This article is freely accessible online.

Correspondence to: Junichiro Watanabe, Division of Breast Oncology, Shizuoka Cancer Center, 1007 Shimonagakubo, Nagaizumi, Sunto-gun, Shizuoka 411-8777, Japan. Tel: +81 559895222, Fax: +81 559895783, e-mail: j.watanabe@scchr.jp

Key Words: Metastatic breast cancer, hepatic arterial infusion chemotherapy, liver metastasis. metastatic breast cancer (MBC) is incurable at present. Despite improvements in systemic therapy, especially in human epidermal growth factor receptor type 2 (HER2)positive subtypes (3), the prognosis of MBC patients with liver metastasis (LM) is not improved (4).

Regimens containing taxane, anthracycline or fluoropyrimidine have been established as first- or secondline systemic therapy for patients with HER2-negative MBC (5), and regimens containing taxane plus anti-HER2 monoclonal antibodies are standard first-line systemic therapy for HER2-positive MBC (5). If following first-line systemic therapy for MBC patients' diseases is still progressing, subsequent chemotherapies, i.e. second-, thirdor later-line systemic therapy, can be performed in addition if patients have maintained a fair condition; however, with limited therapeutic effects on LM (4).

Systemic chemotherapy has been recognized as the mainstay for managing LM from MBC; therefore, local therapies, such as surgical resection (6), radiofrequency ablation (7), radiotherapy (8) or hepatic arterial infusion chemotherapy (HAIC) (9-12), have been conducted as "other options", with "case by case" consideration. Specifically, HAIC has been performed for extensive LM cases that were ineligible for surgical resection or radiofrequency ablation and showed resistance to conventional systemic chemotherapy. Therefore, various regimens in patients with various backgrounds have been reported for HAIC (9-12), and the efficacy of HAIC has not been consistent among reports. Furthermore, the number of patients included in these reports has been relatively small. Therefore, the appropriate regimen and clinical utility of HAIC have not been well discussed as yet.

Arai et al., (10) reported on the use of 5-FU, adriamycin and mitomycin-C (MMC) (FAM) and 5-FU and epirubicin (FE) regimens in the treatment of LM from MBC in 1994. The response rate of LM in their report was $81 \%$. Based on 
their report, we modified the FAM regimen to 5-FU, epirubicin and MMC (FEM) with the aim of reducing cardiac toxicity and used this FEM regimen for HAIC.

The purpose of this retrospective study was to evaluate the clinical efficacy and safety of HAIC with an FEM regimen on LM from MBC that had been resistant to systemic chemotherapies.

\section{Patients and Methods}

Patients. We retrospectively examined MBC patients with LM who underwent HAIC with an FEM regimen at our institute between January 2003 and December 2017. MBC patients who showed resistance to conventional systemic chemotherapy and maintained a performance status (PS) $\leq 2$ according to the Eastern Cooperative Oncology Group (ECOG) (13) PS were included in this study. Resistance to conventional systemic chemotherapy was defined as resistance to taxane, anthracycline and fluoropyrimidine in HER2negative $\mathrm{MBC}$ or resistance to standard anti-HER2 therapies, including taxane and trastuzumab in HER2-positive MBC. HAIC was conducted as a salvage treatment for the MBC patients with extensive and life-threatening LM when other extra-LM was controlled. The application of HAIC was discussed by the multidisciplinary tumor board of our institution. This study was approved by our institutional review committee (Approval number; 30-J11-30-1-3) and met the standards set forth in the Declaration of Helsinki (14).

Treatment procedures. A catheter with a side hole was inserted into the gastroduodenal artery via the left thoracoacromial artery or left subclavian artery and was connected to an injection port implanted subcutaneously in the left subclavian space. A port-catheter system was placed via the side hole method reported by Tanaka et al. (15). The FEM regimen: i) 5 -FU at $330 \mathrm{mg} / \mathrm{m}^{2}$ weekly, ii) epirubicin at $20 \mathrm{mg} / \mathrm{m}^{2}$ every 4 weeks, and iii) MMC at $2.7 \mathrm{mg} / \mathrm{m}^{2}$ biweekly, was administered by a transcatheter bolus injection via the port-catheter system. 5-FU, epirubicin and MMC were administered when the white blood cell (WBC) count was $\geq 3000 / \mu l$ and the platelet (PLT) count was $\geq 100,000 / \mu 1$. 5-FU alone was only administered when the WBC count was $2000-3000 / \mu l$ or the PLT count was 50,000 $100,000 / \mu 1$. HAIC was withheld when the WBC count was $<2000 / \mu l$ or the PLT count was $<50,000 / \mu 1$. No concomitant systemic therapies were administered during HAIC, except for endocrine therapy in cases of hormone receptor (HR)-positive lesions, trastuzumab in cases of HER2-positive lesions or bone-modifying agent, in cases of osteolytic lesions. A written informed consent for radiological intervention and treatment was obtained from all of the study participants.

Efficacy and toxicity assessments. The tumor response was assessed according to the guidelines of the Response Evaluation Criteria in Solid Tumors (RECIST) version 1.1 (16) by contrast-enhanced computed tomography every six to eight weeks. Hematologic and nonhematologic toxicities were evaluated based on the National Cancer Institute Common Terminology Criteria for Adverse Events (version 4.03) (17). Complications related to catheter use during HAIC were also reviewed.

Statistical analyses. Continuous variables were presented as median and range, and categorical variables as number and percentage. The overall survival (OS) was calculated as the period from the initiation of HAIC to death from any cause. The duration of response (DoR) was defined as the period from first achievement of any response to progressive disease (PD) or death by any cause. Data from patients who were alive at their last follow-up date were censored. The date of data cut off was February 28, 2019. Kaplan-Meier curves of estimated OS and DoR were generated, and comparisons between subgroups were performed using a log-rank test. To evaluate the efficacy of HAIC according to each patient's characteristics, univariate and multivariate Cox regression analyses for the OS were applied. Univariate factors with a $p$-Value $<0.05$ were then analyzed using the multivariate Cox regression analysis to test their independence. To avoid multicollinearity, Pearson's correlation coefficients were calculated among laboratory parameters with a $p$-Value $<0.05$ in univariate Cox regression analyses. If a correlation coefficient between two variables was more than 0.6 or less than -0.6 , only the one with the greatest significance in the univariate analysis was included in the multivariate analysis. A two-sided $p$-value $<0.05$ was considered significant. All statistical analyses were conducted using the EZR software, version 1.32 (Saitama Medical Center, Jichii Medical University, Saitama, Japan) (18).

\section{Results}

Patients' characteristics. We identified 87 female patients who received HAIC with FEM regimen within the observation period. Of these 87 patients, 57 (66\%) met inclusion criteria for the current study. Of the 30 patients who were excluded from the analysis, $29 \mathrm{did}$ not meet the criteria for systemic chemotherapy resistance, and 1 had an ECOG PS of 3. The patients' characteristics are shown in Table I. During the HAIC period, 24 out of $47(51 \%)$ HR-positive patients received concomitant endocrine therapy, and trastuzumab was continued in 8 out of 14 (57\%) HER2-positive patients.

The efficacy analyses for intra- and extra-LMs. All patients had evaluable LMs according to the RECIST version 1.1 criteria (16). The objective response [complete response (CR) and partial response (PR)] rate (ORR) of LMs was 63\% [95\% confidence interval $(\mathrm{CI})=49-76]$ (36 out of 57 patients) (Figure 1). The median OS from the initiation of HAIC was 11.3 months (95\%CI=8.5-15.6) (Figure 2A). In the HER2-negative group, the median OS was not affected by the period [before or after the approval of bevacizumab and eribulin methylate (eribulin) in Japan] of initiating HAIC ( $p=0.084$, Figure 2B). In patients whose $\mathrm{LM}$ achieved $\mathrm{CR}$ or PR, the median DoR of LM was 6.4 months (95\% CI=4.5-9.5) (Figure 2C).

The univariate and multivariate Cox regression analyses for the OS are shown in Table II. Univariate Cox regression analysis identified eight significant prognostic factors: i) ECOG PS, ii) HR, iii) maximum size of LM, iv) presence of extra-LM, v) serum aspartate transaminase level (AST) and vi) serum alanine aminotransferase level (ALT), vii) serum total bilirubin level and viii) serum lactate dehydrogenase level. Of these eight factors, all factors except ALT were 
Table I. Patient characteristics

\begin{tabular}{|c|c|c|c|}
\hline & All $(n=57)$ & HER2-/unknown $(\mathrm{n}=42 / 1)$ & HER2 $+(n=14)$ \\
\hline Median age, years (range) & $56(30-80)$ & $55(42-80)$ & $58(30-76)$ \\
\hline \multicolumn{4}{|l|}{ ECOG PS, $\mathrm{n}(\%)$} \\
\hline 0 & $43(75)$ & $33(77)$ & $10(71)$ \\
\hline 1 & $11(19)$ & $7(16)$ & $4(29)$ \\
\hline 2 & $3(5.3)$ & $3(7.0)$ & 0 \\
\hline Recurrent breast cancer, $\mathrm{n}(\%)$ & $52(91)$ & $39(91)$ & $12(86)$ \\
\hline Median number of previous systemic regimens, $\mathrm{n}$ (range)* & $6(3-17)$ & $6(3-17)$ & $6(3-10)$ \\
\hline \multicolumn{4}{|l|}{ Period of initiation of HAIC, n (\%); } \\
\hline Through 2009 & $44(77)$ & $35(81)$ & $9(64)$ \\
\hline From 2010 & $13(23)$ & $8(19)$ & $5(36)$ \\
\hline \multicolumn{4}{|l|}{ Histology of the primary lesion, $\mathrm{n}(\%)$} \\
\hline Invasive ductal carcinoma & $49(86)$ & $35(81)$ & $14(100)$ \\
\hline Invasive lobular carcinoma & $2(3.5)$ & $2(4.7)$ & 0 \\
\hline Other/unknown & $6(11)$ & $6(14)$ & 0 \\
\hline \multicolumn{4}{|l|}{ Receptor status, n (\%) } \\
\hline HR+/HER2+ & $10(18)$ & 0 & $10(71)$ \\
\hline HR+/HER2- & $37(65)$ & $37(86)$ & 0 \\
\hline HR-/HER2+ & $4(7)$ & 0 & $4(29)$ \\
\hline HR-/HER2- & $6(11)$ & $6(14)$ & 0 \\
\hline Median number of liver metastases (range) & $8(1-\geq 20)$ & $10(1-\geq 20)$ & $4(1-15)$ \\
\hline$\geq 5, \mathrm{n}(\%)$ & $36(63)$ & $31(72)$ & $5(36)$ \\
\hline$\leq 4, \mathrm{n}(\%)$ & $21(37)$ & $12(28)$ & $9(64)$ \\
\hline Median maximum size of liver metastasis, $\mathrm{cm}$ (range) & $5.2(1.6-20.1)$ & $4.6(1.6-13.4)$ & $5.7(2.4-20.1)$ \\
\hline$\geq 5 \mathrm{~cm}, \mathrm{n}(\%)$ & $31(55)$ & $21(49)$ & $10(71)$ \\
\hline$<5 \mathrm{~cm}, \mathrm{n}(\%)$ & $26(46)$ & $22(51)$ & $4(29)$ \\
\hline \multicolumn{4}{|l|}{ Tumor distribution of liver metastasis, $\mathrm{n}(\%)$} \\
\hline Bilobar & $46(81)$ & $37(86)$ & $9(64)$ \\
\hline Unilobar & $5(8.8)$ & $2(4.7)$ & $3(21)$ \\
\hline Segmental & $6(11)$ & $4(9.3)$ & $2(14)$ \\
\hline \multicolumn{4}{|l|}{ Extra-liver metastasis, n (\%) } \\
\hline Yes & $45(79)$ & $37(86)$ & $8(57)$ \\
\hline No & $12(21)$ & $6(14)$ & $6(43)$ \\
\hline Median number of extra-liver metastases (range) & $1(0-5)$ & $1(0-5)$ & $1(0-3)$ \\
\hline \multicolumn{4}{|l|}{ Metastatic site, $\mathrm{n}(\%)$} \\
\hline Bone & $34(60)$ & $29(67)$ & $5(36)$ \\
\hline Lymph node & $26(46)$ & $19(44)$ & $7(50)$ \\
\hline Lung & $14(25)$ & $11(26)$ & $3(21)$ \\
\hline Brain & $7(12)$ & $6(14)$ & $1(7.1)$ \\
\hline Pleura & $5(8.8)$ & $5(12)$ & 0 \\
\hline Alb g/dl; median (range) & $4.10(2.7-4.8)$ & $4.1(2.7-4.8)$ & $4.2(2.9-4.5)$ \\
\hline$<$ LLN, n $(\%)$ & $13(23)$ & $10(23)$ & $3(21)$ \\
\hline$\geq \operatorname{LLN}, \mathrm{n}(\%)$ & $44(77)$ & $33(77)$ & $11(79)$ \\
\hline AST U/1; median (range) & $45(16-328)$ & $38(16-328)$ & $55(16-161)$ \\
\hline$>$ ULN, n (\%) & $30(53)$ & $21(49)$ & $9(64)$ \\
\hline$\leq \mathrm{ULN}, \mathrm{n}(\%)$ & $27(47)$ & $22(51)$ & $5(36)$ \\
\hline ALT U/l; median (range) & $27(10-409)$ & $26(10-228)$ & $32(11-409)$ \\
\hline$>$ ULN, $\mathrm{n}(\%)$ & $20(35)$ & $15(35)$ & $5(36)$ \\
\hline$\leq \mathrm{ULN}, \mathrm{n}(\%)$ & $37(65)$ & $28(65)$ & $9(64)$ \\
\hline T-bil U/l; median (range) & $0.5(0.3-3.0)$ & $0.50(0.3-3.0)$ & $0.6(0.3-2.1)$ \\
\hline$>$ ULN, n (\%) & $9(16)$ & $7(16)$ & $2(14)$ \\
\hline$\leq \mathrm{ULN}, \mathrm{n}(\%)$ & $48(84)$ & $36(84)$ & $12(86)$ \\
\hline LDH U/1; median (range) & $293(135-3245)$ & $274(135-3245)$ & $368(153-1888)$ \\
\hline$>$ ULN, $\mathrm{n}(\%)$ & $41(72)$ & $30(70)$ & $11(79)$ \\
\hline$\leq \mathrm{ULN}, \mathrm{n}(\%)$ & $16(28)$ & $13(30)$ & $3(21)$ \\
\hline
\end{tabular}

*Including perioperative chemotherapy, endocrine therapy and anti-HER2 therapy. HER2: Human epidermal growth factor receptor Type 2; ECOG PS: Eastern Cooperative Oncology Group performance status; HAIC: hepatic arterial infusion chemotherapy; HR: hormone receptor; cm: centimeter; Alb: serum albumin level; AST: serum aspartate transaminase level; ALT: serum alanine aminotransferase level; T-bil: serum total bilirubin level; LDH: serum lactate dehydrogenase level; LLN: lower limit of normal; ULN: upper limit of normal. 


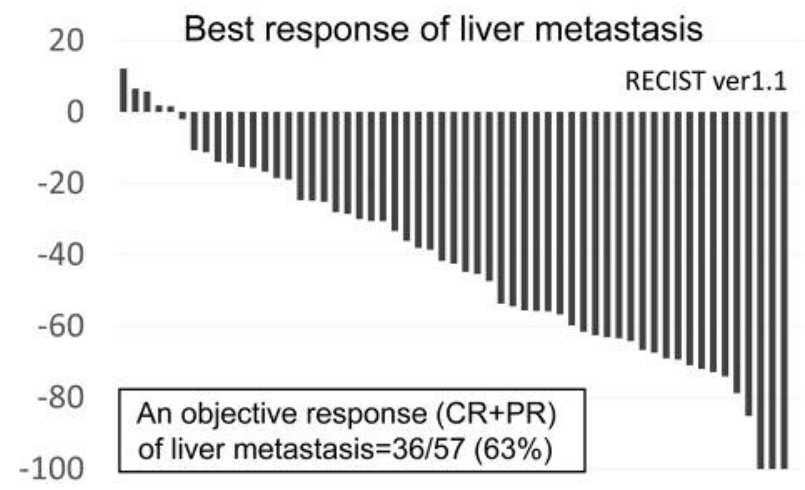

Figure 1. The response of the liver metastasis. A waterfall plot of patients with metastatic breast cancer measuring the maximum reduction (from baseline) in the sum of the longest diameter of liver metastasis based on the Response Evaluation Criteria in Solid Tumors (RECIST) version 1.1 (16). CR: Complete response; PR: partial response.

included in the multivariate Cox regression analysis because the Pearson's correlation coefficient between AST and ALT was equal to 0.632 . The multivariate Cox regression analysis identified two poor prognostic factors (PPFs): i) HR-negative status and ii) the presence of extra-LM. A response of LM was not influenced by PPFs. Among patients without PPFs, any response of LM was achieved in $7 / 11$ patients $(64 \%$, $95 \% \mathrm{CI}=31-89)$. Similarly, a response was observed in $24 / 37$ patients $(65 \%, 95 \% \mathrm{CI}=48-80)$ among patients with $1 \mathrm{PPF}$, and in $5 / 9$ patients $(56 \%, 95 \% \mathrm{CI}=21-86)$ among patients with 2 PPFs. By contrast, there was a distinct difference $(p<0.001)$ in the median OS among patients without PPFs, those with $1 \mathrm{PPF}$, and those with 2 PPFs [25.1 months (95\% CI=16-67.9) vs. 11.3 months (95\% CI=9.1-14.5) vs. 4.9 months $(95 \% \mathrm{CI}=2.0-8.5)$, respectively, Figure 3].

Toxicities. Grade (Gr) $\geq 3$ toxicities included: i) leukopenia $(\mathrm{n}=20,35 \%), \quad \mathrm{ii})$ neutropenia $(\mathrm{n}=20,35 \%)$, iii) thrombocytopenia $(n=13,23 \%)$, iv) increased AST $(n=5$, $8.8 \%), v)$ increased ALT $(n=4,7.0 \%)$ and vi) duodenal ulcer $(\mathrm{n}=1,1.8 \%)$. No treatment-related death, bleeding events or symptomatic cardiac events were observed during the observation period. Catheter-related events were observed in $12(21 \%)$ patients, including kinked catheter $(n=2,3.5 \%)$, stenosis of the hepatic artery $(n=5,8.8 \%)$, abdominal pain caused by extrahepatic flow $(n=3,5.3 \%)$ and $\mathrm{Gr} 2$ cerebral infarction $(n=2,3.5 \%)$. Termination of HAIC due to catheterrelated events occurred in 6 patients $(11 \%)$.

\section{Discussion}

The purpose of systemic therapy for MBC patients is to prolong the OS and maintain their quality of life. LM is known to be a poor prognostic factor in such patients (19), and extensive LM is directly associated with hepatic failure causing death (20). Thus, the control of LM may prolong a patient's OS. However, the efficacy of chemotherapy generally decreases in the late-line treatment compared to front-line treatment (21). Eribulin monotherapy, as a whole, can significantly improve the OS in HER2-negative MBC patients who are resistant to anthracycline and taxane compared to treatment of physician's choice, as was demonstrated in the EMBRACE study (22). In that study, the median OS of the eribulin arm was reported to be 13.2 months, and the ORR of the patients was only $12 \%$. In contrast, the median OS in our study was 11.3 months, and the ORR was $63 \%$. Most of our patients responded to HAIC with the FEM regimen. While there were some differences in patients' backgrounds between these two studies, HAIC with the FEM regimen might be an alternative to eribulin for MBC patients with extensive LM. In the present study, eribulin was administered before HAIC in only 5 of 57 patients; therefore, a further study is necessary to evaluate the efficacy of HAIC following eribulin treatment.

We compared the OS by HER2 status and period of HAIC initiation because the prognosis in HER2-negative patients was relatively poor, and newly developed anticancer drugs, such as capecitabine, S-1, vinorelbine, gemcitabine, bevacizumab and eribulin, were approved during the observation period. However, the HER2 status and period of starting HAIC therapy did not affect OS in MBC patients who received HAIC in combination with an FEM regimen. The HER2 status and history of chemotherapeutic regimens may therefore not influence the indication of HAIC.

Our results suggest that the FEM regimen might be suitable for HAIC. Arai et al., (10) have reported $81 \%$ ORR of LM from MBC with the FAM and FE regimens. LM has also shown a good response to HAIC with 5-FU and adriamycin (ORR, 54\%) (9). The therapeutic efficacy of HAIC with other regimens was also reported recently. Tewes et al., (11) have reported HAIC with 5-FU and MMC (ORR, 24\%), while Hsiao, et al., (12) have reported HAIC with mitoxantrone, folinic acid, 5-FU and cisplatin (ORR, 48\%). Our results are comparable to these previous reports. Furthermore, the toxicities observed during the HAIC therapy in our study are also similar to those described in previous reports $(9,11,12)$. The toxicities related to anticancer agents in the present study were tolerable and manageable. Therefore, the FEM regimen may be a candidate regimen for HAIC.

We identified two PPFs, i) the HR-negative status and ii) the presence of extra-LM. These PPFs are clinically reasonable. Triple-negative MBC is generally aggressive (23), and concomitant endocrine therapy cannot be used to maintain extra-LM in such HR-negative patients. HAIC is not suitable for controlling extra-LM. The prognosis in patients with 2 PPF was markedly worse compared to those with 0-1 PPF, thus, HAIC may also not be suitable for patients with 2 

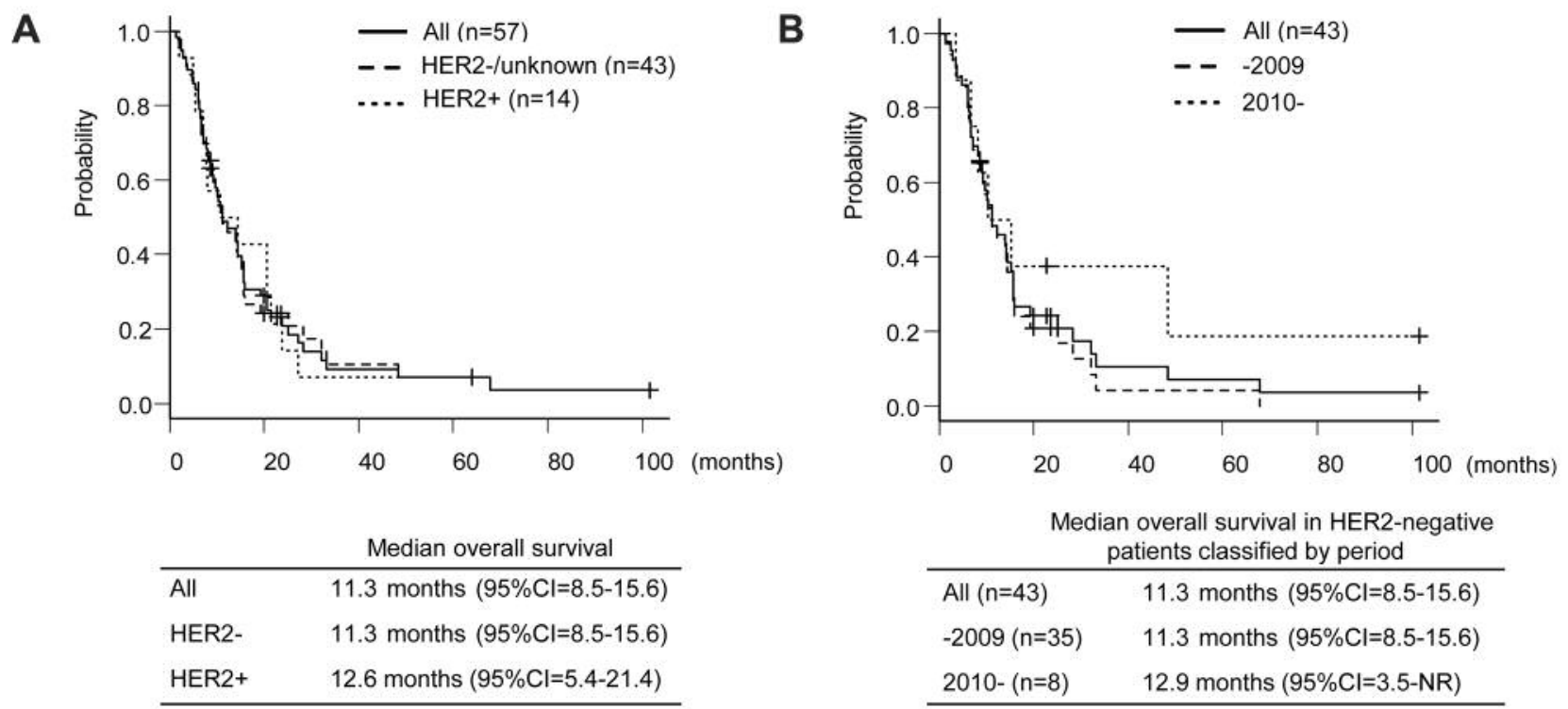

\begin{tabular}{ll} 
& Median overall survival \\
\hline All & 11.3 months $(95 \% \mathrm{Cl}=8.5-15.6)$ \\
HER2- & 11.3 months $(95 \% \mathrm{Cl}=8.5-15.6)$ \\
HER2+ & 12.6 months $(95 \% \mathrm{Cl}=5.4-21.4)$ \\
\hline
\end{tabular}

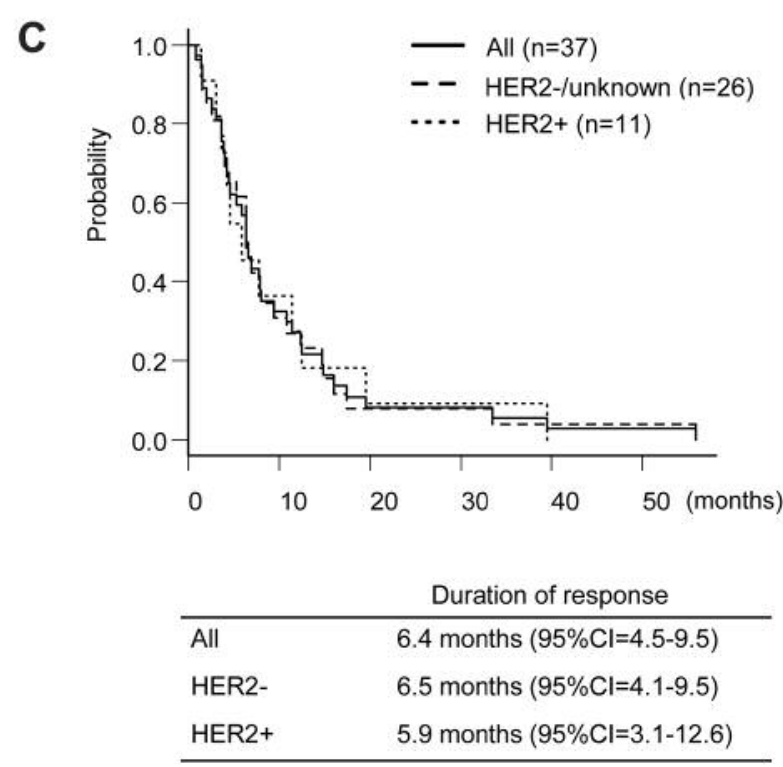

Figure 2. Treatment outcomes. A. The overall survival (OS) stratified by the human epidermal growth factor receptor Type2 (HER2) status. B. The OS in HER2-negative patients classified by period. C. The duration of response of liver metastasis classified by HER2 status. CI: Confidence interval.

PPFs. On the other hand, the clinical outcome in patients with 0-1 PPF indicated that HAIC was reasonable to be considered as a salvage treatment for such patients. While the PPFs identified in the present study must be validated, these PPFs may be useful for predicting the treatment outcome of MBC patients treated with HAIC and have potential application in determining the indication of HAIC.

Catheter-related events were observed in 12 out of 57 $(21 \%)$ patients, which was consistent with previous reports $(9,10)$ in which the incidence rate of catheter-related events was reported to be $20 \%-31 \%$. It is difficult to predict the incidence of catheter-related events. Therefore, the portcatheter system should be checked constantly by contrast angiography via the port-catheter system or X-ray in order to detect catheter-related events early.

Several limitations associated with the present study warrant mention. First, this study was a retrospective one. Second, this study did not include a control arm that was treated with standard systemic therapies. Third, we were unable to exclude selection biases (i.e. the study population included a large 
Table II. Median of overall survival for subgroups and Cox regression analysis.

\begin{tabular}{|c|c|c|c|}
\hline & \multirow{2}{*}{$\frac{\text { Overall survival }}{\text { Median, months }(95 \% \mathrm{CI})}$} & \multicolumn{2}{|c|}{ Cox regression analysis } \\
\hline & & $\begin{array}{c}\text { Univariate analysis } \\
\text { Hazard ratio (95\%CI, } p \text {-Value) }\end{array}$ & $\begin{array}{c}\text { Multivariate analysis* } \\
\text { Hazard ratio (95\% CI, } p \text {-Value) }\end{array}$ \\
\hline All patients, $n=57$ & $11.3(8.5-15.6)$ & & \\
\hline \multicolumn{4}{|l|}{ Age } \\
\hline$\geq 60, n=22$ & $10.4(6.1-16)$ & $0.961(0.543-1.70, p=0.893)$ & \\
\hline$<60, \mathrm{n}=35$ & $14.2(8.2-15.8)$ & 1 & \\
\hline \multicolumn{4}{|l|}{ ECOG PS } \\
\hline $1 / 2, n=14$ & $14.5(8.5-20.5)$ & $2.360(1.238-4.499, p=0.009)$ & $1.831(0.895-3.747, p=0.098)$ \\
\hline $0, \mathrm{n}=43$ & $9.2(3.5-14)$ & 1 & 1 \\
\hline \multicolumn{4}{|l|}{ Period of HAIC } \\
\hline From 2010-, n=13 & $10.8(6.8-48.4)$ & $0.613(0.301-1.248, p=0.177)$ & \\
\hline Through $2009, \mathrm{n}=44$ & $11.3(8.0-15.6)$ & 1 & \\
\hline \multicolumn{4}{|l|}{ Hormone receptor } \\
\hline,$+ \mathrm{n}=47$ & $14.5(10.4-19.3)$ & $0.142(0.0635-0.320, p<0.001)$ & $0.0203(0.082-0.502, p<0.001)$ \\
\hline,$- \mathrm{n}=10$ & $5.2(2.0-7.2)$ & 1 & 1 \\
\hline \multicolumn{4}{|l|}{ HER2 status } \\
\hline HER2,$+ \mathrm{n}=14$ & $12.6(5.5-21.4)$ & $1.006(0.532-1.898, p=0.985)$ & \\
\hline HER2-, $n=43$ & $11.3(8.5-15.6)$ & 1 & \\
\hline \multicolumn{4}{|l|}{ No. of liver lesions } \\
\hline$\geq 5, n=36$ & $9.8(7.2-14.3)$ & $1.74(0.964-3.138, p=0.066)$ & \\
\hline$\leq 4, n=21$ & $15.7(7.8-25.2)$ & 1 & \\
\hline \multicolumn{4}{|c|}{ Maximum size of liver metastasis } \\
\hline$\geq 5 \mathrm{~cm}, \mathrm{n}=31$ & $9.3(10.4-11.3)$ & $1.935(1.098-3.41, p=0.022)$ & $1.944(0.971-3.892, p=0.060)$ \\
\hline$<5 \mathrm{~cm}, \mathrm{n}=26$ & $15.7(10.4-21.4)$ & 1 & 1 \\
\hline \multicolumn{4}{|l|}{ Extra-liver metastasis } \\
\hline Yes, $\mathrm{n}=45$ & $10.1(7.2-14.0)$ & $3.971(1.738-9.074, p=0.001)$ & $3.476(1.365-8.853, p=0.009)$ \\
\hline No, $n=12$ & $23.8(7.8-67.9)$ & 1 & 1 \\
\hline \multicolumn{4}{|l|}{ Alb g/dl } \\
\hline$<$ LLN, $\mathrm{n}=13$ & $6.6(2.5-10.4)$ & $1.761(0.911-3.402, p=0.092)$ & \\
\hline$\geq \mathrm{LLN}, \mathrm{n}=44$ & $14.2(9.8-16)$ & 1 & \\
\hline \multicolumn{4}{|l|}{ AST U/1 } \\
\hline$>$ ULN, $\mathrm{n}=30$ & $7.0(6.0-9.3)$ & $4.393(2.397-8.05, p<0.001)$ & $1.938(0.908-4.136, p=0.087)$ \\
\hline$\leq \mathrm{ULN}, \mathrm{n}=27$ & $20.7(14.5-28.2)$ & 1 & 1 \\
\hline \multicolumn{4}{|l|}{ ALT U/1 } \\
\hline$>$ ULN, $n=20$ & $6.6(4.9-9.8)$ & $3.244(1.781-5.908, p<0.001)$ & \\
\hline$\leq \mathrm{ULN}, \mathrm{n}=37$ & $15.6(11.1-21.4)$ & 1 & \\
\hline \multicolumn{4}{|l|}{ T-bil U/l } \\
\hline$>$ ULN, $\mathrm{n}=9$ & $6.6(1.3-8.5)$ & $2.196(1.009-4.778, p=0.047)$ & $2.567(0.990-6.656, p=0.052)$ \\
\hline$\leq \mathrm{ULN}, \mathrm{n}=48$ & $14.2(10.1-15.8)$ & 1 & 1 \\
\hline \multicolumn{4}{|l|}{$\mathrm{LDH} \mathrm{U/1}$} \\
\hline$>$ ULN, $\mathrm{n}=41$ & $8.5(6.7-11.1)$ & $4.883(2.223-10.73, p<0.001)$ & $1.466(0.520-4.137, p=0.469)$ \\
\hline$\leq \mathrm{ULN}, \mathrm{n}=16$ & $28.2(14.5-67.9)$ & 1 & 1 \\
\hline
\end{tabular}

*Eastern Cooperative Oncology Group performance status (ECOG PS), hormone receptor, maximum size of liver metastasis, presence of extraliver metastasis, serum aspartate transaminase level (AST), serum total bilirubin level (T-bil) and serum lactate dehydrogenase level (LDH) were included in the multivariate Cox regression analysis. Serum alanine aminotransferase level (ALT) was excluded due to multicollinearity between AST and ALT ( $r=0.623)$. CI: Confidence interval; HAIC: hepatic arterial infusion chemotherapy; HER2: human epidermal growth factor receptor Type 2; cm: centimeter; Alb: serum albumin level; LLN: lower limit of normal; ULN: upper limit of normal.

number of patients highly selected by their conditions associated with extra-LM). However, the observation period was long enough and we were able to follow most patients until their death. In most cases, the catheter port was inserted by an interventional radiology specialist. Therefore, our data, such as the OS and catheter-related events, may be reliable.
In conclusion, HAIC with an FEM regimen was effective for treating $\mathrm{LM}$ from $\mathrm{MBC}$ refractory to conventional systemic chemotherapy. However, there are concerns about the progression of extra-LM and catheter-related events. Therefore, the indication of HAIC should be decided carefully with consideration of poor prognostic factors, such 


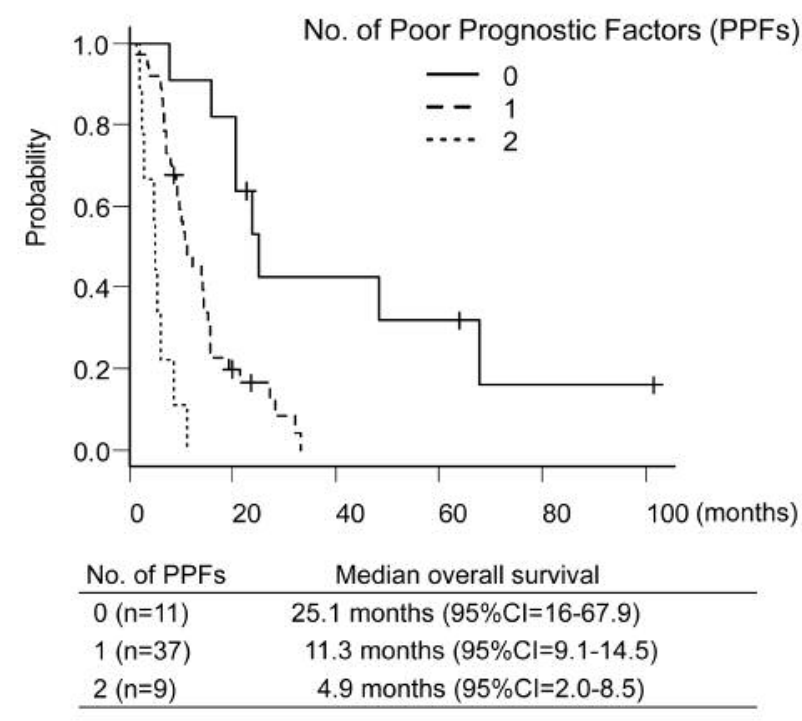

Figure 3. The overall survival classified by the number of poor prognostic factors (PPFs) (0 versus 1 versus 2). CI: Confidence interval.

as the HR status and the presence of extra-LM. A prospective, randomized study is warranted.

\section{Conflicts of Interest}

The Authors declare no conflicts of interest regarding this study.

\section{Authors' Contributions}

MF, JW, and AN participated in literature research and drafting the article. MF, JW and TA participated in treating patients. MF and AN participated in analyzing the study data. HY edited the final version of article. All Authors have read and approved of the final manuscript.

\section{Acknowledgements}

The Authors would like to thank all of the patients and their families, as well as the staff members of Shizuoka Cancer Center. The Authors also thank Mr. Brian Quinn, editor-in-chief of Japan Medical Communication, for the linguistic assistance in revising our manuscript.

\section{References}

1 Bray F, Ferlay J, Soerjomataram I, Siegel RL, Torre LA and Jemal A: Global cancer statistics 2018: Globocan estimates of incidence and mortality worldwide for 36 cancers in 185 countries. CA Cancer J Clin 68(6): 394-424, 2018. PMID: 30207593. DOI: $10.3322 /$ caac. 21492

2 Asselain B, Barlow W, Bartlett J, Bergh J, Bergsten-Nordström E, Bliss J, Boccardo F, Boddington C, Bogaerts J, Bonadonna G, Bradley R, Brain E, Braybrooke J, Broet P, Bryant J, Burrett J,
Cameron D, Clarke M, Coates A, Coleman R, Coombes RC, Correa C, Costantino J, Cuzick J, Danforth D, Davidson N, Davies C, Davies L, Di Leo A, Dodwell D, Dowsett M, Duane F, Evans V, Ewertz M, Fisher B, Forbes J, Ford L, Gazet J-C, Gelber R, Gettins L, Gianni L, Gnant M, Godwin J, Goldhirsch A, Goodwin P, Gray R, Hayes D, Hill C, Ingle J, Jagsi R, Jakesz R, James S, Janni W, Liu H, Liu Z, Lohrisch C, Loibl S, MacKinnon L, Makris A, Mamounas E, Mannu G, Martín M, Mathoulin S, Mauriac L, McGale P, McHugh T, Morris P, Mukai H, Norton L, Ohashi Y, Olivotto I, Paik S, Pan H, Peto R, Piccart M, Pierce L, Poortmans P, Powles T, Pritchard K, Ragaz J, Raina V, Ravdin P, Read S, Regan M, Robertson J, Rutgers E, Scholl S, Slamon D, Sölkner L, Sparano J, Steinberg S, Sutcliffe R, Swain S, Taylor C, Tutt A, Valagussa P, van de Velde C, van der Hage J, Viale G, von Minckwitz G, Wang Y, Wang Z, Wang X, Whelan T, Wilcken N, Winer E, Wolmark N, Wood W, Zambetti M and Zujewski JA: Long-term outcomes for neoadjuvant versus adjuvant chemotherapy in early breast cancer: Meta-analysis of individual patient data from ten randomised trials. Lancet Oncol 19(1): 27-39, 2018. PMID: 29242041. DOI: 10.1016/s1470-2045(17)30777-5

3 Gobbini E, Ezzalfani M, Dieras V, Bachelot T, Brain E, Debled M, Jacot W, Mouret-Reynier MA, Goncalves A, Dalenc F, Patsouris A, Ferrero JM, Levy C, Lorgis V, Vanlemmens L, Lefeuvre-Plesse C, Mathoulin-Pelissier S, Petit T, Uwer L, Jouannaud C, Leheurteur M, Lacroix-Triki M, Cleaud AL, Robain M, Courtinard C, Cailliot C, Perol D, Delaloge S: Time trends of overall survival among metastatic breast cancer patients in the real-life ESME cohort. Eur J Cancer 96: 17-24, 2018. PMID: 29660596. DOI: 10.1016/j.ejca.2018.03.015

4 Holzel D, Eckel R, Bauerfeind I, Baier B, Beck T, Braun M, Ettl J, Hamann U, Kiechle M, Mahner S, Schindlbeck C, de Waal J, Harbeck $\mathrm{N}$ and Engel J: Improved systemic treatment for early breast cancer improves cure rates, modifies metastatic pattern and shortens post-metastatic survival: 35-year results from the munich cancer registry. J Cancer Res Clin Oncol 143(9): 1701-1712, 2017. PMID: 28429102. DOI: 10.1007/s00432-017-2428-0

5 Cardoso F, Senkus E, Costa A, Papadopoulos E, Aapro M, Andre F, Harbeck N, Aguilar Lopez B, Barrios CH, Bergh J, Biganzoli L, Boers-Doets CB, Cardoso MJ, Carey LA, Cortes J, Curigliano G, Dieras V, El Saghir NS, Eniu A, Fallowfield L, Francis PA, Gelmon K, Johnston SRD, Kaufman B, Koppikar S, Krop IE, Mayer M, Nakigudde G, Offersen BV, Ohno S, Pagani O, Paluch-Shimon S, Penault-Llorca F, Prat A, Rugo HS, Sledge GW, Spence D, Thomssen C, Vorobiof DA, Xu B, Norton L and Winer EP: 4th eso-esmo international consensus guidelines for advanced breast cancer (abc 4). Ann Oncol 29(8): 1634-1657, 2018. PMID: 30032243. DOI: 10.1093/annonc/mdy192

6 Ruiz A, van Hillegersberg R, Siesling S, Castro-Benitez C, Sebagh M, Wicherts DA, de Ligt KM, Goense L, Giacchetti S, Castaing D, Morere $\mathrm{J}$ and Adam R: Surgical resection versus systemic therapy for breast cancer liver metastases: Results of a european case matched comparison. Eur J Cancer 95: 1-10, 2018. PMID: 29579478. DOI: 10.1016/j.ejca.2018.02.024

7 Bale R, Richter M, Dunser M, Levy E, Buchberger W and Schullian P: Stereotactic radiofrequency ablation for breast cancer liver metastases. J Vasc Interv Radiol 29(2): 262-267, 2018. PMID: 29273283. DOI: 10.1016/j.jvir.2017.09.027

8 Onal C, Guler OC and Yildirim BA: Treatment outcomes of breast cancer liver metastasis treated with stereotactic body radiotherapy. Breast 42: 150-156, 2018. PMID: 30296648. DOI: $10.1016 /$ j.breast .2018 .09 .006 
9 Ikeda T AI, Takashima S, Ogita M, Aoyama H, Sano M, Ando J, Tabei T, Tominaga T, Enomoto K, Kanda K, Fukutomi T and Shimoyama M: A phase I/II study of continuous intra-arterial chemotherapy using an implantable reservoir for the treatment of liver metastases from breast cancer: A japan clinical oncology group (JCOG) study 9113. JCOG breast cancer study group. Jpn J Clin Oncol 29(1): 23-27, 1999. PMID: 10073147. DOI: 10.1093/jjco/29.1.23

10 Arai Y, Sone Y, Inaba Y, Ariyoshi Y and Kido C: Hepatic arterial infusion chemotherapy for liver metastases from breast cancer. Cancer Chemother Pharmacol 33 Suppl(Suppl): S142-144, 1994. PMID: 8137476. DOI: 10.1007/BF00686687

11 Tewes M, Peis MW, Bogner S, Theysohn JM, Reinboldt MP, Schuler M and Welt A: Hepatic arterial infusion chemotherapy for extensive liver metastases of breast cancer: Efficacy, safety and prognostic parameters. J Cancer Res Clin Oncol 143(10): 21312141, 2017. PMID: 28646261. DOI: 10.1007/s00432-017-2462-y

12 Hsiao JH, Chang HT, Tseng YD, Chiang CL, Chen IS, Chen YC, Chang PM and Wang BW: Hepatic arterial infusion chemotherapy is a feasible treatment option for breast cancer with liver-predominant metastatic disease. In Vivo 32(6): 16351641, 2018. PMID: 30348727. DOI: 10.21873/invivo.11425

13 Oken MM, Creech RH, Tormey DC, Horton J, Davis TE, McFadden ET, Carbone PP: Toxicity and response criteria of the Eastern Cooperative Oncology Group. Am J Clin Oncol 5(6): 649-55, 1982. PMID 7165009.

14 World Medical Association: World Medical Association Declaration of Helsinki: ethical principles for medical research involving human subjects. JAMA 310(20): 2191-2194, 2013. PMID: 24141714. DOI: 10.1001/jama.2013.281053

15 Tanaka T, Arai Y, Inaba Y, Matsueda K, Aramaki T, Takeuchi Y and Kichikawa K: Radiologic placement of side-hole catheter with tip fixation for hepatic arterial infusion chemotherapy. J Vasc Interv Radiol 14(1): 63-68, 2003. PMID: 12525587. DOI: 10.1097/01.Rvi.0000052292.26939.59

16 Eisenhauer EA, Therasse P, Bogaerts J, Schwartz LH, Sargent D, Ford R, Dancey J, Arbuck S, Gwyther S, Mooney M, Rubinstein L, Shankar L, Dodd L, Kaplan R, Lacombe D and Verweij J: New response evaluation criteria in solid tumours: Revised recist guideline (version 1.1). Eur J Cancer 45(2): 228247, 2009. PMID: 19097774. DOI: 10.1016/j.ejca.2008.10.026

17 The Cancer Therapy Evaluation Program of the National Cancer Institute. Available at: http://ctep.cancer.gov/protocol Development/ electronic_applications/ctc.htm\#ctc_40 (Accessed Sep 29, 2019)
18 Kanda Y: Investigation of the freely available easy-to-use software 'ezr' for medical statistics. Bone Marrow Transplant 48(3): 452-458, 2013. PMID: 23208313. DOI: 10.1038/bmt. 2012.244

19 Yamamura J, Kamigaki S, Tsujie M, Fujita J, Osato H, Higashi C, Kanaizumi H, Tanaka Y, Hamada M, Shinzaki W, Hashimoto Y, Komoike Y: Response to first-line recurrence treatment influences survival in hormone receptor-positive, HER2-negative breast cancer: A multicenter study. In Vivo 33(1): 281-287, 2019. PMID: 30587637. DOI: 10.21873/invivo.11473

20 Diamond JR, Finlayson CA and Borges VF: Hepatic complications of breast cancer. Lancet Oncol 10(6): 615-621, 2009. PMID: 19482250. DOI: 10.1016/S1470-2045(09)70029-4

21 Bonotto M, Gerratana L, Iacono D, Minisini AM, Rihawi K, Fasola G, Puglisi F: Treatment of metastatic breast cancer in a real-world scenario: Is progression-free survival with first line predictive of benefit from second and later lines? Oncologist 20(7): 719-724, 2015. PMID: 26018662. DOI: 10.1634/ theoncologist.2015-0002

22 Cortes J, O'Shaughnessy J, Loesch D, Blum JL, Vahdat LT, Petrakova K, Chollet P, Manikas A, Diéras V, Delozier T, Vladimirov V, Cardoso F, Koh H, Bougnoux P, Dutcus CE, Seegobin S, Mir D, Meneses N, Wanders J and Twelves C: Eribulin monotherapy versus treatment of physician's choice in patients with metastatic breast cancer (embrace): A phase 3 open-label randomised study. Lancet 377(9769): 914-923, 2011. PMID: 21376385. DOI: 10.1016/s0140-6736(11)60070-6

23 Hwang KT, Kim J, Jung J, Chang JH, Chai YJ, Oh SW, Oh S, Kim YA, Park SB and Hwang KR: Impact of breast cancer subtypes on prognosis of women with operable invasive breast cancer: A population-based study using seer database. Clin Cancer Res 25(6): 1970-1979, 2019. PMID: 30559169. DOI: 10.1158/1078-0432.CCR-18-2782
Received September 8, 2019

Revised October 1, 2019

Accepted October 14, 2019 